\title{
Social play behavior, ultrasonic vocalizations and their modulation by morphine and amphetamine in Wistar and Sprague-Dawley rats
}

\author{
Antonia Manduca • Patrizia Campolongo • \\ Maura Palmery • Louk J. M. J. Vanderschuren • \\ Vincenzo Cuomo • Viviana Trezza
}

Received: 4 June 2013 / Accepted: 12 October 2013 / Published online: 13 November 2013

(C) Springer-Verlag Berlin Heidelberg 2013

\begin{abstract}
Rationale Social play behavior is the most characteristic social behavior in young mammals. It is highly rewarding and crucial for proper neurobehavioral development. Despite the importance of genetic factors in normal and pathological social behaviors, little information is available about strain influences on social play.

Objective and methods The aim of this study was to investigate differences in social play behavior, $50-\mathrm{kHz}$ ultrasonic vocalizations (USVs) and their modulation by acute morphine and amphetamine administration in two rat strains widely used in behavioral pharmacology studies, i.e., Wistar and SpragueDawley rats.

Results Sprague-Dawley rats showed higher levels of social play than Wistar rats. In both strains, no correlation was found between the performance of social behaviors and the emission of 50-kHz USVs. In Wistar and Sprague-Dawley rats, morphine increased and amphetamine decreased social play. The
\end{abstract}

\footnotetext{
A. Manduca $\cdot$ V. Trezza $(\bowtie)$

Department of Science, Section of Biomedical Sciences and Technologies, University "Roma Tre", Viale G. Marconi 446, 00146 Rome, Italy

e-mail: viviana.trezza@uniroma3.it

P. Campolongo $\cdot$ M. Palmery $\cdot$ V. Cuomo

Department of Physiology and Pharmacology, Sapienza,

University of Rome, Rome, Italy

L. J. M. J. Vanderschuren

Department of Translational Neuroscience, Brain Center

Rudolf Magnus, University Medical Center Utrecht, Utrecht,

The Netherlands

L. J. M. J. Vanderschuren

Department of Animals in Science and Society, Division of Behavioural Neuroscience, Faculty of Veterinary Medicine, Utrecht University, Utrecht, The Netherlands
}

effects of morphine, however, were more pronounced in Wistar than Sprague-Dawley animals. In both strains, morphine did not affect USV emission, while amphetamine increased it during cage exploration. In Sprague-Dawley rats only, amphetamine decreased USVs during social interaction. Conclusions Wistar and Sprague-Dawley rats differ in their absolute levels of social play behavior and $50-\mathrm{kHz}$ USVs, and quantitative differences exist in their response to pharmacological manipulations of social play. The emission of $50-\mathrm{kHz}$ USVs and the behavioral parameters thought to reflect rewarding social interactions in adolescent rats are dissociable.

Keywords Social behavior · USV · Adolescence · Opioids . Psychostimulants

\section{Introduction}

Social play behavior is the first form of non-parent directed social behavior displayed by most mammalian species (Panksepp et al. 1984; Pellis and Pellis 2009; Vanderschuren et al. 1997). The experience of social play behavior inbetween weaning and sexual maturity is crucial for proper social and cognitive development (Baarendse et al. 2013; Panksepp et al. 1984; Pellis and Pellis 2009; Spinka et al. 2001; Van den Berg et al. 1999; Vanderschuren et al. 1997; Von Frijtag et al. 2002), and abnormalities in social play behavior have been observed in developmental psychiatric disorders, such as autism and attention deficit/hyperactivity disorder (Alessandri 1992; Jordan 2003; Manning and Wainwright 2010). In line with its importance for proper neurobehavioral development, social play behavior is a highly rewarding activity (Calcagnetti and Schechter 1992; Crowder and Hutto 1992; Douglas et al. 2004; Falk 1958; Humphreys and Einon 1981; Ikemoto and Panksepp 1992; Mason et al. 
1963; Normansell and Panksepp 1990; Thiel et al. 2008; Thiel et al. 2009; Trezza et al. 2009; for reviews see Trezza et al. 2010, 2011a; Vanderschuren 2010).

Genetic factors profoundly affect the development and expression of social behavior from birth to adulthood, and they contribute to normal variation in social behavior between individuals (Ebstein et al. 2010; O'Connell and Hofmann 2010). However, they also play a major role in aberrant social behavior and psychopathology (Meyer-Lindenberg and Tost 2012). Therefore, a better understanding of the extent to which a particular genotype affects social behavior is an important issue in social neuroscience research.

Despite its crucial role in development, to date limited information is available about genetic influences on social play behavior (Ferguson and Cada 2004; Siviy et al. 2003; Reinhart et al. 2006; Siviy et al. 2011). To address this issue, we investigated whether baseline differences in social play behavior exist between adolescent male Wistar and SpragueDawley rats. These two outbred strains are widely used in behavioral pharmacology studies (Hedrich 2006; McDermott and Kelly 2008) and are the two preferred rat strains used in developmental neurotoxicity testing in Europe and North America (Clause 1993; Zmarowski et al. 2012). At adulthood, rats from these two strains are known to differ in a wide range of emotional-related behaviors (Rex et al. 2004; Staples and McGregor 2006; Walker et al. 2009), including social interactions (Rex et al. 2004). Therefore, we hypothesized that they also differ in adolescent social play behavior.

During social interactions, rats emit ultrasonic vocalizations (USVs) which are considered a measure of affective states and a means of communication (Knutson et al. 2002; Lahvis et al. 2011; Scattoni et al. 2009; Takahashi et al. 2010; Wohr and Schwarting 2013). In rats, low-frequency (around $22-\mathrm{kHz}$ ) USVs have been associated with negative social experiences (e.g., exposure to predator odor, inter-male fighting), while high frequency (around 50-kHz) USVs have been detected in social contexts involving potential reward (e.g., sexual approach, play fighting) (Burgdorf et al. 2011). For this reason, we also investigated whether adolescent Wistar and Sprague-Dawley rats showed a different pattern of USV emission during active social interactions.

We and others have previously shown that opioid and psychostimulant drugs have opposite effects on social play behavior. Thus, systemic administration of opioid receptor agonists such as morphine enhances social play, while psychostimulants such as methylphenidate or amphetamine suppress it (Siviy and Panksepp 2011; Trezza et al. 2010). Opioid neurotransmission is thought to mediate the rewarding and motivational properties of social play behavior (Trezza et al. 2011b), whereas psychostimulants may modulate cognitive aspects of social play behavior (Trezza et al. 2010; Vanderschuren et al. 2008).It has been shown that Wistar and Sprague-Dawley rats show different sensitivity toward the behavioral effects induced by morphine (Mas et al. 2000; Shoaib et al. 1995) and amphetamine (Kinney et al. 1999; McDermott and Kelly 2008) administration. Therefore, we hypothesized that adolescent Wistar and Sprague-Dawley rats also differ in the effects induced by acute morphine and amphetamine administration on social play behavior and USV emission.

\section{Materials and methods}

\section{Animals}

Male Wistar and Sprague-Dawley rats (Charles River Laboratories, Calco, Italy) arrived in our animal facility at 21 days of age and were housed in groups of five in $43 \times$ $26 \times 20 \mathrm{~cm}(l \times w \times h)$ Macrolon cages under controlled conditions (i.e., temperature $21 \pm 1{ }^{\circ} \mathrm{C}, 60 \pm 10 \%$ relative humidity, and 12/12-h light cycle with lights on at 7:00 AM). Food and water were available ad libitum. All animals were experimentally naïve and used only once (i.e., each animal received one injection only, with either drug or vehicle solution). All experiments were approved by the Italian Ministry of Health (Rome, Italy) and performed in agreement with the guidelines released by the Italian Ministry of Health (D.L. 116/92) and the European Community Directive 2010/63/EU of 22 September 2010.

\section{Drugs}

The opioid receptor agonist morphine (SALARS, Como, Italy) and the psychostimulant D-amphetamine sulfate (RBI, Research Biochemicals International, MA, USA) were dissolved in saline and given subcutaneously (s.c.) $1 \mathrm{~h}$ and $30 \mathrm{~min}$ before testing, respectively. For the dose-response experiments shown in Figs. 1 and 4, three drug doses $(0.3$, 1 , and $3 \mathrm{mg} / \mathrm{kg}$ of morphine; $0.05,0.2$, and $0.5 \mathrm{mg} / \mathrm{kg}$ of amphetamine) were tested. On the basis of these results, for the experiments shown in Figs. 2, 3, 5, and 6, we used the lowest doses of morphine $(1 \mathrm{mg} / \mathrm{kg})$ and amphetamine $(0.2 \mathrm{mg} / \mathrm{kg})$ that significantly affected social play behavior in both strains. Drug doses and pretreatment intervals were based on our previous experiments and literature data (Beatty et al. 1982; Field and Pellis 1994; Trezza et al. 2010; Trezza and Vanderschuren 2008a; Vanderschuren et al. 1995a, c). We used doses of morphine and amphetamine that are known to have minimal effects on locomotor activity and do not evoke stereotyped behaviors (Bolanos et al. 1998; Fowler et al. 2003; Kuczenski and Segal 1999; Magnus-Ellenbroek and Havemann-Reinecke 1993; Trezza and Vanderschuren 2008a; Vezina and Queen 2000). Solutions were freshly prepared on the day of the experiment and were administered in a 

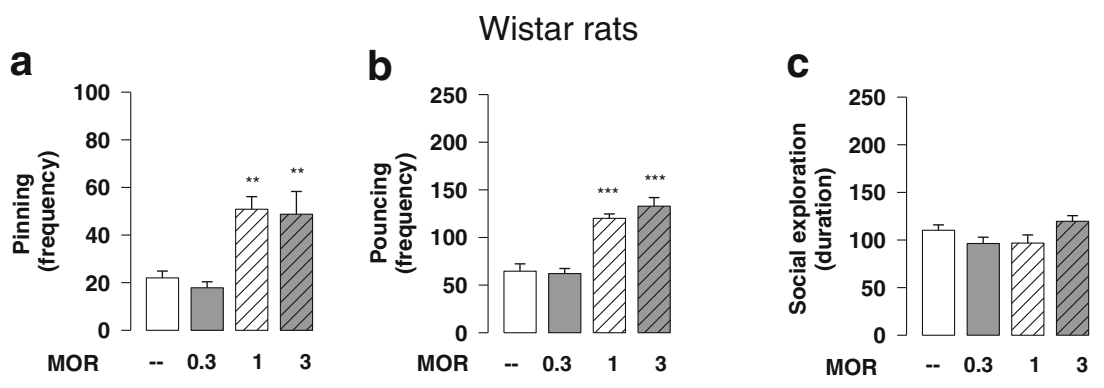

\section{Sprague-Dawley rats}
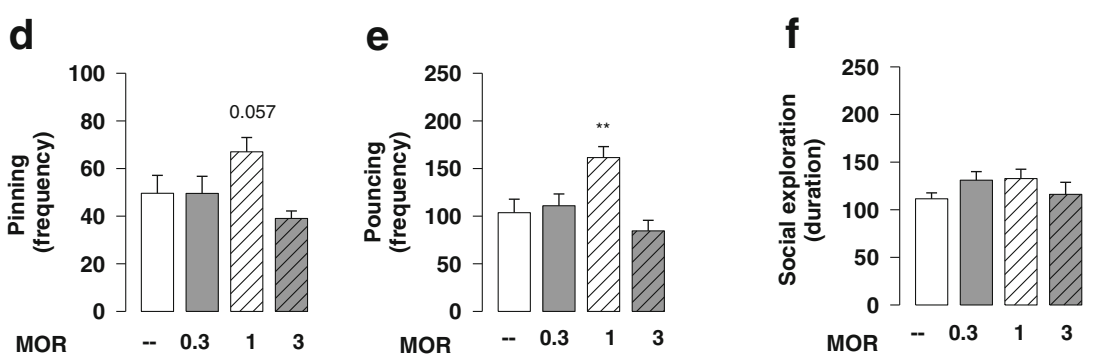

Fig. 1 Effects of graded doses of the opioid receptor agonist morphine (MOR; $0.3,1$, and $3 \mathrm{mg} / \mathrm{kg}$, s.c., $1 \mathrm{~h}$ before test) on social play behavior in adolescent Wistar and Sprague-Dawley rats. Morphine, at the doses of 1 and $3 \mathrm{mg} / \mathrm{kg}$, increased pinning (a) and pouncing (b) frequency in Wistar rats, with no effect on social exploration (c). In Sprague-Dawley rats,

volume of $2 \mathrm{ml} / \mathrm{kg}$. Because of the importance of the neck area in the expression of social play behavior (Pellis and Pellis morphine, at the dose of $1 \mathrm{mg} / \mathrm{kg}$, induced a trend for an increase in pinning (d) and significantly increased pouncing (e), with no effect on social exploration (f). Data represent mean \pm SEM frequency of pinning and pouncing and mean \pm SEM duration of social exploration. ${ }^{* *} p<0.01$; $* * * p<0.001$ vs. vehicle treatment; $N=7-10$ per treatment group

1987; Siviy and Panksepp 1987), subcutaneous injections were administered in the flank.
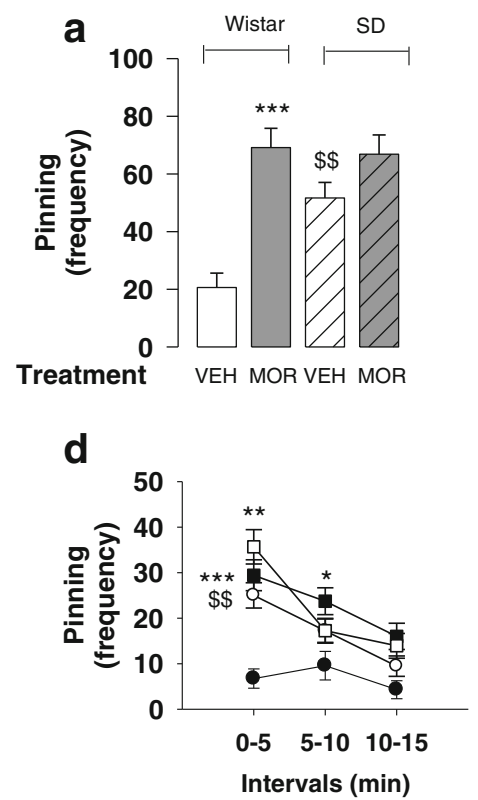
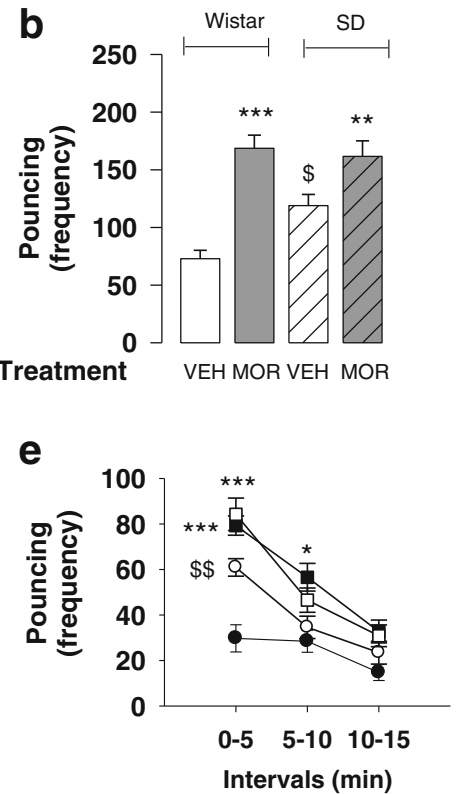
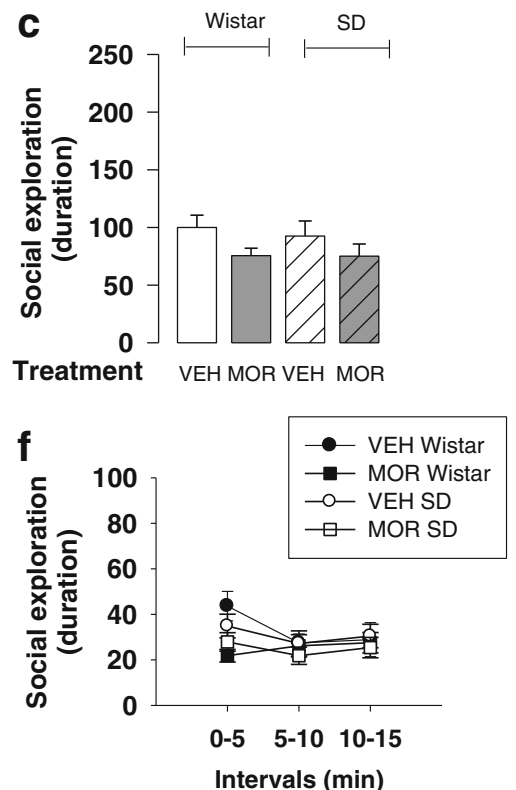

Fig. 2 Effects of the opioid receptor agonist morphine (MOR; $1 \mathrm{mg} / \mathrm{kg}$, s.c., $1 \mathrm{~h}$ before test) on social play behavior in adolescent Wistar and Sprague-Dawley rats. Vehicle-treated Sprague-Dawley rats showed higher levels of pinning (a) and pouncing (b) than vehicle-treated Wistar rats. Morphine administration increased pinning (a) and pouncing (b) in both strains, although its effects on pinning and pouncing were more pronounced in Wistar than in Sprague-Dawley rats. When behaviors were analyzed per 5-min intervals, vehicle-treated Sprague-Dawley rats played more than vehicle-treated Wistar rats during the first 5-min interval of the test (d, e); morphine enhanced pinning (d) and pouncing (e) during the first 5-min interval of the test in both Wistar and SpragueDawley rats. In Wistar rats, morphine also increased pinning and pouncing frequencies (d, e) during the second 5-min periods of the test. No strain or treatment effects were found in the total time spent in general social exploration during social play behavior $(\mathbf{c}, \mathbf{f})$. Data represent mean \pm SEM frequency of pinning and pouncing and mean \pm SEM duration of social exploration. ${ }^{*} p<0.05, * * p<0.01 ; * * * p<0.001$ vs. vehicle treatment; ${ }^{\$} p<0.05,{ }^{\$ \$} p<0.01$ Sprague-Dawley vs. Wistar rats (Student-Newman-Keule post hoc test). $N=7-12$ per treatment group 

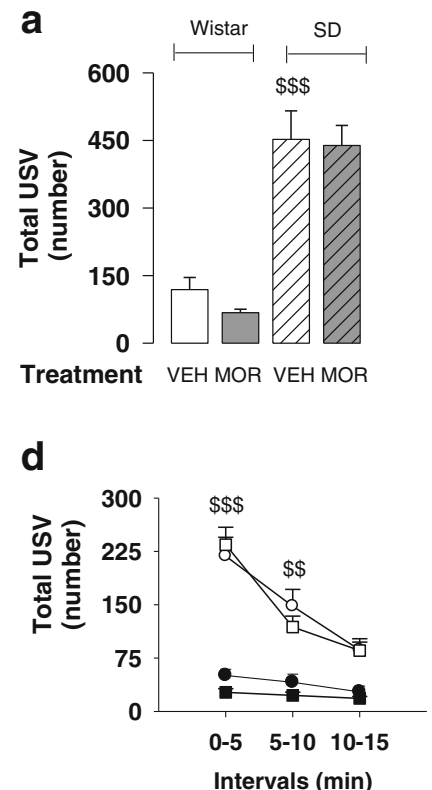

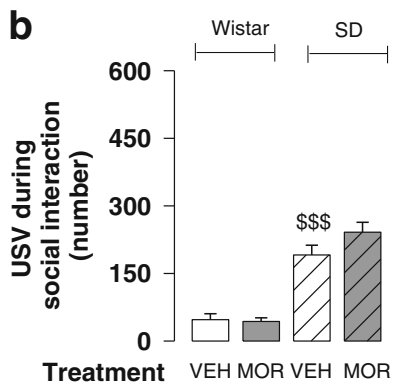

e

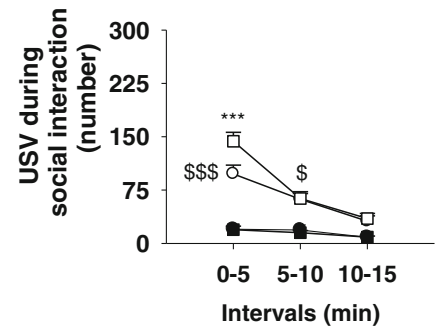

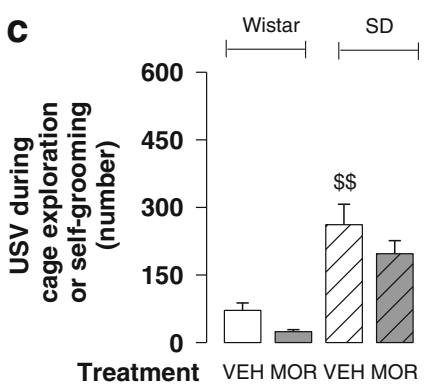

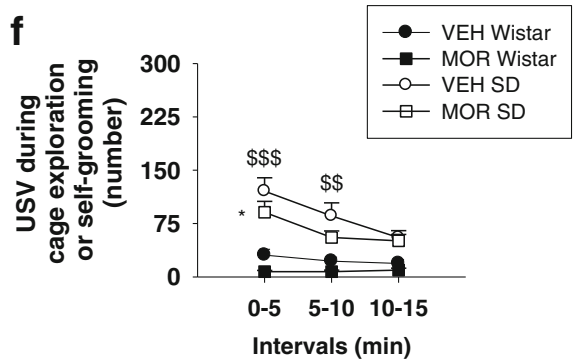

Fig. 3 Effects of morphine (MOR; $1 \mathrm{mg} / \mathrm{kg}$, s.c., $1 \mathrm{~h}$ before test) on 50$\mathrm{kHz}$ ultrasonic vocalizations in adolescent Wistar and Sprague-Dawley rats during the social play behavior session. Over the 15-min test session, vehicle-treated Sprague-Dawley rats emitted more USVs than vehicletreated Wistar rats $(\mathbf{a}, \mathbf{b}, \mathbf{c})$; no effect of morphine treatment on USV emission was found in both strains $(\mathbf{a}, \mathbf{b}, \mathbf{c})$. When behaviors were analyzed per 5-min intervals, vehicle-treated Sprague-Dawley rats emitted more USVs, both related and unrelated to the social interaction, than vehicle-treated Wistar rats during the first and the second 5-min interval of the test session $(\mathbf{d}, \mathbf{e}, \mathbf{f})$. In addition, in the first 5-min interval,

Procedure

\section{Social play behavior}

All the experiments were performed in a sound attenuated chamber under dim light conditions. The testing arena consisted of a Plexiglas cage measuring $40 \times 40 \times 60 \mathrm{~cm}$ $(l \times w \times h)$, with approximately $2 \mathrm{~cm}$ of wood shavings covering the floor. The behavior of the animals was recorded using a video camera with zoom lens, DVD recorder, and LCD monitor.

Social play was assessed as previously described (Trezza et al. 2009; Trezza and Vanderschuren 2008a, b; Vanderschuren et al. 2008). Briefly, at 25-28 days of age, rats were individually habituated to the test cage for $10 \mathrm{~min}$ on each of the two days prior to testing. On the test day, the animals were socially isolated for $3.5 \mathrm{~h}$ before testing to enhance their social motivation and thus facilitate the expression of social play behavior during testing. This isolation period has been shown to induce a half-maximal increase in the amount of social play behavior (Niesink and Van Ree 1989; Vanderschuren et al. 1995a, 2008). At the appropriate time before testing, pairs of animals were treated with drugs or vehicle. The test consisted of placing two similarly treated animals into the test cage for $15 \mathrm{~min}$. The animals of each pair morphine increased the number of USVs emitted by Sprague-Dawley rats during social interaction (e), whereas it decreased the number of USVs emitted by Sprague-Dawley rats during cage exploration and selfgrooming (f). Morphine did not affect USV emission at any time point in Wistar rats. Data represent mean \pm SEM frequency of total USVs $(\mathbf{a}, \mathbf{d})$ and USVs either related $(\mathbf{b}, \mathbf{e})$ and unrelated $(\mathbf{c}, \mathbf{f})$ to the social interaction. ${ }^{*} p<0.05,{ }^{* * *} p<0.001$ vs. vehicle treatment; ${ }^{\$} p<0.05,{ }^{\$} \$ p<0.01$; $\$ \$ \$ p<0.001$ Sprague-Dawley vs. Wistar rats (Student-Newman-Keule post hoc test). $N=7-12$ per treatment group

did not differ more than $10 \mathrm{~g}$ in body weight and had no previous common social experience (i.e., they were not cage mates). Drug treatments were randomized so that cage mates were allocated to different treatment groups.

Behavior was assessed per pair of animals and analyzed by a trained observer who was unaware of treatment condition using the Observer XT software (Noldus, Wageningen, The Netherlands). In rats, a bout of social play behavior starts with one rat soliciting ("pouncing") another animal by attempting to nose or rub the nape of its neck. The animal that is pounced upon can respond in different ways. If the animal that is pounced upon fully rotates to its dorsal surface, "pinning" is the result, i.e., one animal lying with its dorsal surface on the floor with the other animal standing over it. From this position, the supine animal can initiate another play bout by trying to gain access to the other animal's neck. Thus, during social play, pouncing is considered an index of play solicitation, while pinning functions as a releaser of a prolonged play bout (Panksepp and Beatty 1980; Pellis and Pellis 1987; Pellis et al. 1989; Poole and Fish 1975). Pinning and pouncing frequencies can be easily quantified and they are considered to be the most characteristic parameters of social play behavior in rats (Panksepp and Beatty 1980). During the social encounter, animals may also display social behaviors not directly associated with play, such as sniffing or grooming the partner's body 
(Panksepp and Beatty 1980; Vanderschuren et al. 1995c). Since social play behavior in rats strongly depends on the playfulness of its partner (Pellis and McKenna 1992; Trezza and Vanderschuren 2008b), in the present study, both animals in a play pair were similarly treated, and a pair of rats was considered as one experimental unit. The following parameters were therefore scored per pair of animals:

Social behaviors directly related to play:

- frequency of pinning

- frequency of pouncing

Social behaviors unrelated to play:

- time spent in social exploration: the total amount of time spent in non playful forms of social interaction (i.e., one animal sniffing or grooming any part of the partner's body).

\section{Measurement of ultrasonic vocalizations during social interaction}

USVs were recorded as previously described (Burgdorf et al. 2005; Trezza et al. 2008; Willey et al. 2009). The USVs emitted during the social play behavior session were detected by an ultrasonic microphone (SM2, Ultrasound Advice) fixed at $30 \mathrm{~cm}$ above the floor of the test cage in order to record USVs from the whole chamber. The microphone was connected to a Bat Detector (US 30 Ultrasound Advice) tuned to $50 \pm 10 \mathrm{kHz}$ and connected to a high-speed tape recorder (Racal Store). The number of USVs was manually and independently recorded by three experimenters blind to the treatment, by listening to the audible output of the tape recorder through headphones (Philips HI-FI stereo SHP9000). The experimenters were listening to the audible output through headphones while watching the behavior of the animals in the LCD monitor, thus being able to discriminate between the USVs emitted during social-related behaviors (i.e., pinning, pouncing, boxing, sniffing, following, social grooming) and USVs emitted during non social-related behaviors (i.e., cage exploration (rearing, wall rearing, digging) and selfgrooming). The total number of USVs emitted during the 15-min social play testing session was analyzed per pair of animals. Thus, a pair of rats was treated as a single observation. Total USVs represent the sum of USVs emitted during social-related and social-unrelated behaviors.

\section{Statistical analysis}

Pinning and pouncing frequencies and time spent in social exploration were calculated per pair of animals and expressed as mean \pm SEM. The USVs emitted during social-related and social-unrelated behaviors and the total number of USVs emitted during the 15-min test session were calculated per pair of animals and expressed as mean \pm SEM. Data from the dose-response experiments were analyzed using one-way analysis of variance (ANOVA). To assess the effects of the different strains and treatments on social play behavior and USV production, data were analyzed using two-way ANOVA, using treatment (morphine or amphetamine) and strain (Wistar or Sprague-Dawley) as between-subjects factors. One- and two-way ANOVA were followed by Student-Newman-Keuls post hoc test where appropriate. To assess whether the effects of morphine and amphetamine on social play behavior and USV production in Wistar and Sprague-Dawley rats changed over time, the 15-min test session was divided in three blocks of $5 \mathrm{~min}$, which were analyzed using two-way ANOVA for repeated measures, followed by Student-Newmann-Keuls post hoc test where appropriate. $P$ values of less than 0.05 were considered statistically significant.

\section{Results}

Effects of morphine on social play behavior in adolescent Wistar and Sprague-Dawley rats

Dose-response experiments performed in Wistar and Sprague-Dawley rats showed that morphine administration increased social play behavior in both strains. In Wistar rats, a one-way ANOVA analysis performed on pinning and pouncing frequencies and on duration of social exploration gave the following results: [pinning: $F_{3,26}=9.822, p=0.0002$; pouncing: $F_{3,26}=24.755, p<0.0001$; social exploration: $F_{3,26}=$ 2.731, $p=0.0643]$. Post hoc analysis revealed that morphine (MOR), at the doses of 1 and $3 \mathrm{mg} / \mathrm{kg}$, significantly increased pinning (Fig. 1a; $p<0.01$ ) and pouncing (Fig. 1b; $p<0.001$ ), with no effect on social exploration (Fig. 1c; n.s.). In SpragueDawley rats, a one-way ANOVA analysis performed on pinning and pouncing frequencies and on duration of social exploration gave the following results: [pinning: $F_{3,30}=3.019, p=0.0452$; pouncing: $F_{3,30}=6.630, p=0.0014$; social exploration: $\left.F_{3,30}=1.404, p=0.2608\right]$. Post hoc analysis revealed that morphine, at the dose of $1 \mathrm{mg} / \mathrm{kg}$, significantly increased pouncing (Fig. 1e; $p<0.01$ ), while induced a trend for an increase in pinning (Fig. 1d; $p=0.057$ ). Morphine did not affect social exploration in Sprague-Dawley rats (Fig. 1f; n.s.).

When we compared the effects of morphine $(1 \mathrm{mg} /$ $\mathrm{kg}$ ) on social play behavior in the two strains, we found that the increase in social play induced by morphine was more pronounced in Wistar than in SpragueDawley rats. A two-way ANOVA analysis performed on pinning and pouncing frequencies gave the following results: pinning $\left[F_{\text {(strain)1,31 }}=4.929, p=0.034 ; F_{\text {(treatment) } 1,31}=24.164\right.$, $\left.p<0.001 ; F_{\text {(strain } \times \text { treatment) } 1,31}=6.637, p=0.015\right]$; pouncing $\left[F_{(\text {strain }) 1,31}=2.572, p=0.119 ; F_{\text {(treatment) } 1,31}=32.319\right.$, $\left.p<0.001 ; F_{\text {(strain } x \text { treatment) } 1,31}=4.743, p=0.037\right]$. Post hoc 
analysis revealed that baseline levels of social play behavior were higher in Sprague-Dawley than in Wistar rats. Vehicletreated Sprague-Dawley rats showed higher levels of pinning and pouncing (Fig. 2a, b) than vehicle-treated Wistar rats $(p<$ 0.01 for pinning; $p<0.05$ for pouncing). Morphine administration increased social play behavior in both strains, although its effects on pinning (Fig. 2a) were more pronounced in Wistar $(p<0.001)$ than in Sprague-Dawley rats $(p=0.064)$. As for the time spent in general social exploration, the twoway ANOVA did not show a statistically significant difference between either the two strains or treatment groups: [Fig. 2c: $F_{\text {(strain)1,31 }}=0.117, p=0.735 ; F_{\text {(treatment) } 1,31}=3.345, p=0.077$; $\left.F_{\text {(strain } \times \text { treatment) } 1,31}=0.0928, p=0.763\right]$. When behaviors were analyzed per 5-min intervals, the two-way ANOVA for repeated measures revealed that morphine enhanced pinning (Fig. 2d; $\left[F_{\text {(interval)2,62 }}=25.940, p<0.0001 ; F_{\text {(interval } \times \text { strain)2,62 }}=6.151\right.$, $p=0.0037 ; F_{(\text {interval } \times \text { treatment) } 2,62}=4.080, p=0.0216$; $\left.\left.F_{\text {(interval } \times \text { strain } \times \text { treatment)2,62 }}=0.455, p=0.6364\right]\right)$ and pouncing (Fig. 2e; $\left[F_{\text {(interval)2,62 }}=65.042, p<0.0001\right.$; $F_{\text {(interval } \times \text { strain)2,62 }}=4.778, p=0.0118 ; F_{\text {(interval } \times \text { treatment)2,62 }}=$ $6.581, p=0.0026 ; F_{\text {(interval } \times \operatorname{strain} \times \text { treatment }) 2,62}=0.694$, $p=0.5035])$ in both Sprague-Dawley and Wistar rats and that there were differences in the baseline levels of social play behavior between the two rat strains. Post hoc analysis revealed that vehicle-treated Sprague-Dawley rats played more than vehicle-treated Wistar rats during the first 5 -min interval of the test (Fig. 2d, e; $p<0.01$ for pinning; $p<0.01$ for pouncing). In both Wistar and Sprague-Dawley rats, morphine enhanced pinning (Fig. 2d) and pouncing (Fig. 2e) during the first 5-min interval of the test (pinning: $p<0.001$ for Wistar rats; $p<0.01$ for Sprague-Dawley rats; pouncing: $p<0.001$ for both Wistar and Sprague-Dawley rats). In Wistar rats, morphine also increased pinning and pouncing frequencies during the second 5 -min period of the test (Fig. $2 \mathrm{~d}$, e; $p<0.05$ for both pinning and pouncing). No differences in the total time spent in general social exploration were observed between either strains or treatment groups (Fig. 2f; $\left[F_{\text {(interval)2,62 }}=2.554, p=0.0859 ; F_{\text {(interval } \times \text { strain)2,62 }}=0.064\right.$, $p=0.9381 ; F_{(\text {interval } \times \text { treatment) } 2,62}=2.533, p=0.0876$; $\left.\left.F_{\text {(interval } \times \text { strain } \times \text { treatment)2,62 }}=1.797, p=0.1743\right]\right)$.

Effects of morphine on 50-kHz ultrasonic vocalizations in adolescent Wistar and Sprague-Dawley rats

The rate of USVs emitted during the test session differed between Wistar and Sprague-Dawley rats, with the latter emitting more USVs than the former. In both strains, no correlation was found between the performance of social behaviors and the emission of $50-\mathrm{kHz}$ USVs. Morphine administration had no effects in both strains.

A two-way ANOVA analysis performed on the number of total USVs emitted during the 15-min test session (Fig. 3a) and on the USVs emitted exclusively either during active social interaction (Fig. 3b) or during cage exploration or self-grooming (Fig. 3c) gave the following results: total USVs $\left[F_{\text {(strain)1,31 }}=54.902, p<0.001 ; F_{\text {(treatment) } 1,31}=0.470\right.$, $\left.p=0.498 ; F_{\text {(strain } \times \text { treatment) } 1,31}=0.157 ; p=0.695\right]$; USVs during social interaction $\left[F_{(\text {strain }) 1,31}=70.286, p<0.001\right.$; $F_{\text {(treatment) } 1,31}=1.302, p=0.263 ; F_{\text {(strain } \times \text { treatment) } 1,31}=1.789$, $p=0.191]$; USVs during cage exploration or self-grooming $\left[F_{(\text {strain }) 1,31}=31.186, p<0.001 ; F_{\text {(treatment) } 1,31}=2.952\right.$, $\left.p=0.096 ; F_{(\text {strain } \times \text { treatment) } 1,31}=0.067, p=0.798\right]$. Post hoc analysis revealed that, over the 15 -min testing session, vehicle-treated Sprague-Dawley rats emitted more USVs $(p<0.001)$, either related $(p<0.001)$ or unrelated $(p<0.01)$ to the social interaction, than vehicle-treated Wistar rats (Fig. 3a-c). Furthermore, no effect of morphine treatment on USV emission was found in both rat strains (Fig. 3a-c).

When behaviors were analyzed per 5-min intervals, two-way ANOVA for repeated measures performed on the total number of USVs revealed that Sprague-Dawley rats emitted more USVs than Wistar rats (Fig. 3 d; $\left[F_{\text {(interval)2,62 }}=54.488, p<0.0001\right.$; $F_{\text {(interval } \times \text { strain)2,62 }}=35.426, p<0.0001 ; F_{\text {(interval } \times \text { treatment)2,62 }}=$ 1.091, $\left.p=0.342 ; F_{\text {(interval } \times \text { strain } \times \text { treatment) }, 62}=1.425, p=0.248\right]$ ). The USVs emitted during social interaction (Fig. 3e; $\left[F_{\text {(interval)2,62 }}=42.524, p<0.0001 ; F_{\text {(interval } \times \text { strain)2,62 }}=26.874\right.$, $p<0.0001 ; \quad F_{\text {(interval } \times \text { treatment) } 2,62}=2.877, p=0.0638$; $\left.\left.F_{\text {(interval } \times \operatorname{strain} \times \text { treatment)2,62 }}=2.551, p=0.0861\right]\right)$ and during cage exploration or self-grooming (Fig. 3f; $\left[F_{\text {(interval)2,62 }}=17.889, p<0.0001 ; F_{\text {(interval } \times \text { strain)2,62 }}=12.211\right.$, $p<0.0001 ; F_{\text {(interval } \times \text { treatment)2,62 }}=2.215, p=0.117 ; F_{\text {(interval } \times}$ strain $\times$ treatment)2,62 $=0.553, p=0.578]$ ]) were higher in SpragueDawley than in Wistar rats. Post hoc analysis revealed that vehicle-treated Sprague-Dawley emitted more USVs, either related or unrelated to social interaction, than vehicle-treated Wistar rats during the first (Fig. 3d-f; $p<0.001$ for total number of USVs and for USVs related and unrelated to social interaction) and the second 5-min interval of the test session (Fig. 3d, f; $p<0.01$ for total number of USVs and for USVs during cage exploration or self-grooming; Fig. 3 e; $p<0.05$ for USVs related to social interaction). In the first 5-min interval only, morphine increased the number of USVs emitted by SpragueDawley rats during social interaction (Fig. 3e; $p<0.001$ ), whereas it decreased the number of USVs emitted by Sprague-Dawley rats during cage exploration and selfgrooming (Fig. 3f; $p<0.05$ ). Morphine did not affect USV emission at any time point in Wistar rats (Fig. 3d-f).

Effects of amphetamine on social play behavior in adolescent Wistar and Sprague-Dawley rats

Separate dose-response experiments performed in Wistar and Sprague-Dawley rats showed that amphetamine administration decreased social play behavior in both strains. A one-way ANOVA analysis performed on pinning and pouncing frequencies and on duration of social exploration in either 
Wistar or Sprague-Dawley rats gave the following results: Wistar rats [pinning: $F_{3,29}=14.457, p<0.0001$; pouncing: $F_{3,29}=27.509, p<0.0001$; social exploration: $F_{3,29}=$ 2.368, $p=0.0913$; Fig. 4a-c]; Sprague-Dawley rats [pinning: $F_{3,29}=20.249, p<0.0001 ;$ pouncing: $F_{3,29}=24.658, p<0.0001$; social exploration: $F_{3,29}=2.174$, $p=0.1126$; Fig. $4 \mathrm{~d}-\mathrm{f}]$. Post hoc analysis revealed that amphetamine (AMPH), at the doses of 0.2 and $0.5 \mathrm{mg} / \mathrm{kg}$, significantly decreased pinning (Fig. $4 \mathrm{a} ; p<0.001$; Fig. 4 d; $p<0.001$ ) and pouncing (Fig. $4 \mathrm{~b} ; p<0.001$; Fig. 4e; $p<0.001$ ), with no effect on social exploration (Fig. 4c; n.s.; Fig. 4f; n.s.) in both strains.

When we compared the effects of amphetamine $(0.2 \mathrm{mg} / \mathrm{kg})$ on social play behavior in the two strains, we found that the drug induced quantitatively similar effects in Wistar and Sprague-Dawley rats. A two-way ANOVA performed on pinning and pouncing frequencies gave the following results: pinning $\left[F_{\text {(strain)1,27 }}=12.496, p=0.001 ; F_{\text {(treatment) } 1,27}=41.976\right.$, $\left.p<0.001 ; F_{\text {(strain } \times \text { treatment) } 1,27}=10.409, p=0.003\right]$; pouncing $\left[F_{\text {(strain) } 1,27}=23.805, p<0.001 ; F_{\text {(treatment) } 1,27}=55.153\right.$, $\left.p<0.001 ; F_{\text {(strain } \times \text { treatment) } 1,27}=3.003, p=0.095\right]$. As in the previous experiments, post hoc analysis showed that vehicletreated Sprague-Dawley rats displayed higher pinning and pouncing frequencies than vehicle-treated Wistar rats (Fig. 5a, b; $p<0.001$ for both pinning and pouncing). Amphetamine reduced the frequency of pinning and pouncing in both Wistar and Sprague-Dawley rats (Fig. 5a, b; Wistar rats: $p<0.05$ for pinning and $p<0.001$ for pouncing; SpragueDawley rats: $p<0.001$ for both pinning and pouncing).

No strain or treatment effects were found in the total time spent in general social exploration during social play behavior
$\left(\left[F_{(\text {strain }) 1,27}=0.0782, p=0.782 ; F_{\text {(treatment) } 1,27}=2.157\right.\right.$, $p=0.832 ; F_{\text {(strain } \times \text { treatment) } 1,27}=0.431, p=0.517 ;$ Fig. $\left.5 \mathrm{c}\right]$.

When behaviors were analyzed per 5 -min intervals, twoway ANOVA for repeated measures gave the following results: pinning $\left[F_{\text {(interval)2,54 }}=15.931, p<0.0001 ; F_{\text {(interval } \times \text { strain) } 2,54}=\right.$ $7.510, p=0.0013 ; F_{\text {(interval } \times \text { treatment) } 2,54}=12.167, p<0.001$; $\left.F_{\text {(interval } \times \text { strain } \times \text { treatment)2,54 }}=5.300, p=0.0079\right]$; pouncing $\left[F_{\text {(interval)2,54 }}=49.624, p<0.0001 ; F_{\text {(interval } \times \text { strain)2,54 }}=11.012\right.$, $p<0.0001 ; F_{(\text {interval } \times \text { treatment) } 2,54}=4.716, p=0.0129$; $F_{\text {(interval } \times \text { strain } \times \text { treatment)2,54 }}=0.147, p=0.8632$ ]; social exploration $\left[F_{(\text {interval) } 2,54}=11.406, p<0.0001 ; F_{\text {(interval } \times \text { strain) } 2,54}=\right.$ $0.642, p=0.5301 ; F_{\text {(interval } \times \text { treatment) } 2,54}=1.559, p=0.2196$; $\left.F_{\text {(interval } \times \text { strain } \times \text { treatment)2,54 }}=1.084, p=0.3455\right]$. Post hoc comparisons revealed that vehicle-treated Sprague-Dawley rats showed higher pinning (Fig. $5 \mathrm{~d} ; p<0.001$ ) and pouncing (Fig. 5e; $p<0.001$ ) frequencies than vehicle-treated Wistar rats in the first 5-min interval of the test. In both strains, amphetamine reduced the frequency of pinning and pouncing during the first 5-min interval (Wistar rats: $p<0.01$ for pinning and $p<0.001$ for pouncing; Sprague-Dawley rats: $p<0.001$ for both pinning and pouncing). In Sprague-Dawley rats, amphetamine decreased pinning and pouncing in the second 5-min interval as well (Fig. 5d, e; $p<0.05$ for both pinning and pouncing), with no effects on social exploration in either strain (Fig. 5f).

Effects of amphetamine on $50-\mathrm{kHz}$ ultrasonic vocalizations in adolescent Wistar and Sprague-Dawley rats

As in the previous experiment, Sprague-Dawley rats emitted more USVs than Wistar rats and the performance of social
Fig. 4 Effects of graded doses of amphetamine (AMPH; 0.05, 0.2, and $0.5 \mathrm{mg} / \mathrm{kg}$, s.c., $30 \mathrm{~min}$ before test) on social play behavior in adolescent Wistar and SpragueDawley rats. Amphetamine, at the doses of 0.2 and $0.5 \mathrm{mg} / \mathrm{kg}$, decreased pinning $(\mathbf{a}, \mathbf{d})$ and pouncing $(\mathbf{b}, \mathbf{e})$ frequency in both Wistar and Sprague-Dawley rats, with no effect on social exploration $(\mathbf{c}, \mathbf{f})$. Data represent mean \pm SEM frequency of pinning and pouncing and mean \pm SEM duration of social exploration. $* * * p<0.001$ vs. vehicle treatment; $N=7-10$ per treatment group
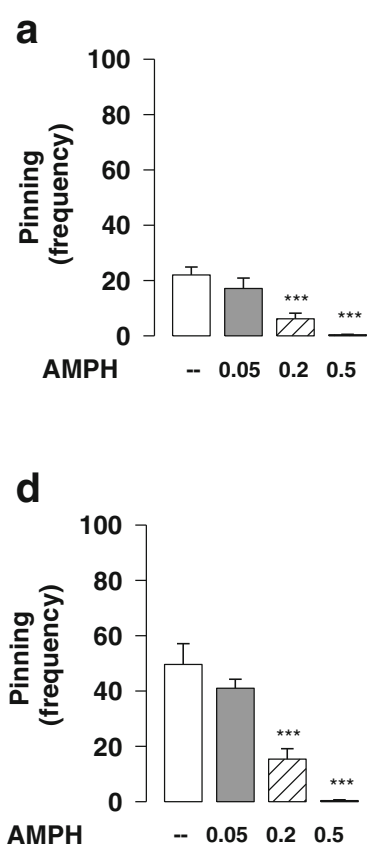

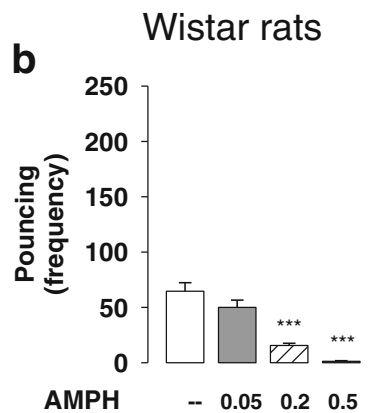

\section{Sprague-Dawley rats}

e



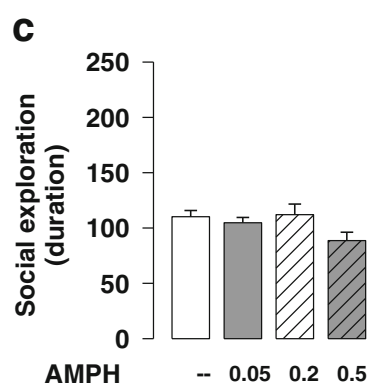

f

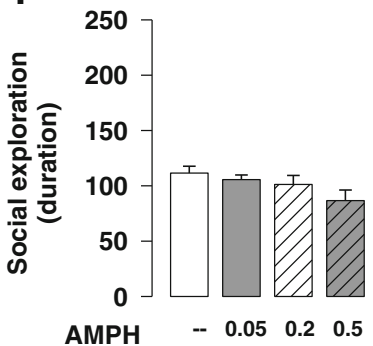



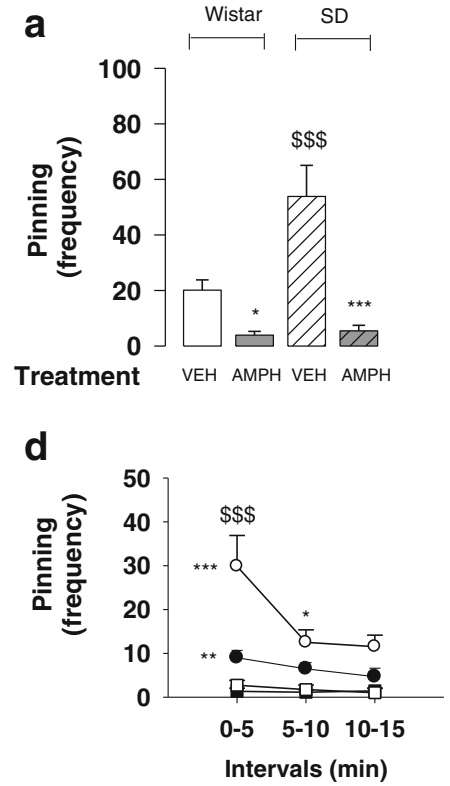

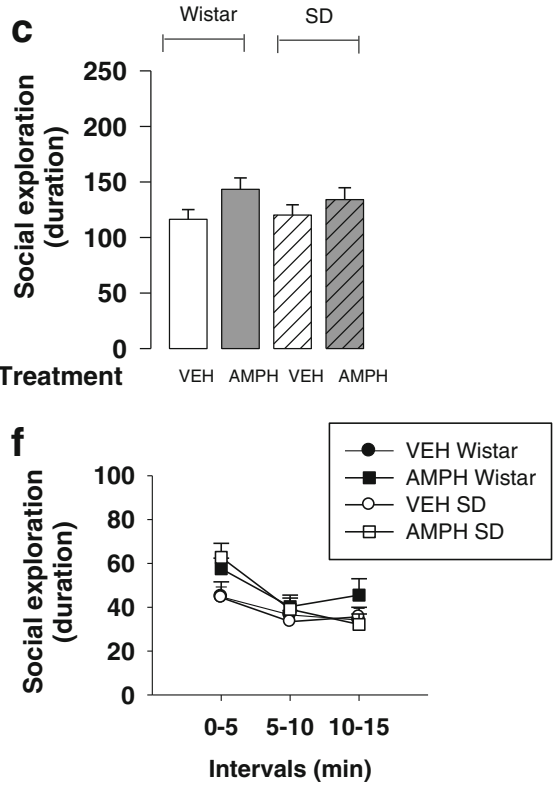

Fig. 5 Effects of amphetamine (AMPH; $0.2 \mathrm{mg} / \mathrm{kg}$, s.c., $30 \mathrm{~min}$ before test) on social play behavior in adolescent Wistar and Sprague-Dawley rats. Vehicle-treated Sprague-Dawley rats played more than vehicletreated Wistar rats $(\mathbf{a}, \mathbf{b})$. Amphetamine decreased the frequency of pinning (a) and pouncing (b) in both rat strains. When behaviors were analyzed per 5-min interval, vehicle-treated Sprague-Dawley rats showed higher pinning (d) and pouncing (e) frequencies than vehicletreated Wistar rats in the first 5-min interval of the test. Amphetamine

behaviors was unrelated to the emission of $50-\mathrm{kHz}$ USVs. Amphetamine administration increased the number of USVs emitted during cage exploration or self-grooming in both strains. In Sprague-Dawley rats only, amphetamine decreased the USVs emitted during social interaction.

A two-way ANOVA analysis performed on the number of total USVs emitted during the 15-min test session and on the USVs emitted exclusively either during social interaction or during cage exploration and self-grooming gave the following results: total USVs emitted: $\left[F_{\text {(strain)1,27 }}=22.694, p<0.001\right.$; $F_{\text {(treatment) } 1,27}=0.156, p=0.696 ; F_{\text {(strain } \times \text { treatment) } 1,27}=0.631$, $p=0.434]$, Fig. 6a; USVs emitted during active social interaction: $\left[F_{\text {(strain)1,27 }}=16.391, p<0.001 ; F_{\text {(treatment) } 1,27}=15.824\right.$, $\left.p<0.001 ; F_{\text {(strain } \times \text { treatment) } 1,27}=2.673, p=0.114\right]$ ], Fig. 6b; USVs emitted during cage exploration and self-grooming: $\left[F_{(\text {strain) } 1,27}=12.613, p=0.001 ; F_{\text {(treatment) } 1,27}=11.063\right.$, $\left.p=0.003 ; F_{\text {(strain } \times \text { treatment) } 1,27}=0.007, p=0.935\right]$, Fig. 6c). Post hoc analysis indicated that vehicle-treated SpragueDawley rats emitted more USVs than vehicle-treated Wistar rats during the 15 -min testing session (Fig. $6 \mathrm{a} ; p<0.01$ ), both during active social interaction (Fig. $6 \mathrm{~b} ; p<0.01$ ) and during cage exploration or self-grooming (Fig. 6c; $p<0.05$ ).

Post hoc analysis showed that Sprague-Dawley rats treated with amphetamine emitted less USVs during active social interaction than vehicle-treated Sprague-Dawley rats (Fig. 6b; $p<0.01$ ). Conversely, amphetamine-treated Sprague-Dawley and Wistar rats emitted more USVs during reduced the frequency of pinning (d) and pouncing (e) in both Wistar and Sprague-Dawley rats during the first 5-min interval and only in SpragueDawley rats in the second 5-min interval. No strain or treatment effects were found in the total time spent in general social exploration $(\mathbf{c}, \mathbf{f})$. Data represent mean \pm SEM frequency of pinning and pouncing and mean \pm SEM duration of social exploration. ${ }^{*} p<0.05, * * p<0.01 ; * * * p<0.001$ vs. vehicle treatment; ${ }^{\$ \$} p<0.001$ Sprague-Dawley vs. Wistar rats (Student-Newman-Keule post hoc test). $N=6-9$ per treatment group

cage exploration and self-grooming (Fig. $6 \mathrm{c} ; p<0.05$ for both Wistar and Sprague-Dawley rats) than the corresponding vehicle-treated rats.

When ultrasonic vocalizations were analyzed per 5-min intervals, vehicle-treated Sprague-Dawley rats emitted more USVs than vehicle-treated Wistar rats (total USVs emitted: $\left[F_{\text {(interval) } 2,54}=53.308, p<0.0001\right.$; $F_{\text {(interval } \times \text { strain)2,58 }}=7.367, p=0.0015 ; F_{\text {(interval } \times \text { treatment)2,54 }}=$ $6.751, p=0.0024 ; F_{\text {(interval } \times \text { strain } \times \text { treatment) } 2,54}=1.084$, $p=0.3454]$, Fig. 6d; USVs emitted during social interaction: $\left[F_{\text {(interval)2,54 }}=35.047, p<0.0001 ; F_{\text {(interval } \times \text { strain)2,54 }}=\right.$ $9.068, p<0.0004 ; F_{\text {(interval } \times \text { treatment) } 2,54}=8.197$, $p=0.0008 ; F_{\text {(interval } \times \text { strain } \times \text { treatment) } 2,54=2.096,}$ $p=0.1329$ ], Fig. 6e; USVs emitted during cage exploration: $\left[F_{\text {(interval)2,54 }}=7.014, p=0.002 ; F_{\text {(interval } \times \text { strain)2,54 }}=\right.$ $1.253, p=0.2937 ; F_{\text {(interval } \times \text { treatment) } 2,54}=0.476, p=0.6241$; $\left.F_{\text {(interval } \times \text { strain } \times \text { treatment)2,58 }}=0.255, p=0.776\right]$, Fig. 6f).

Post hoc analysis revealed that the total number of USVs, both related and unrelated to social behavior, was higher in vehicle-treated Sprague-Dawley than vehicle-treated Wistar rats during the first $(p<0.001)$ and the second $(p<0.05) 5$-min intervals of the testing session (Fig. 6d). USVs emitted selectively during either social interaction (Fig. 6e) or cage exploration and self grooming (Fig. 6f) were higher in vehicletreated Sprague-Dawley than vehicle-treated Wistar rats during the first and second 5-min intervals of the test, respectively (USVs during social interaction in the first 5-min interval: 

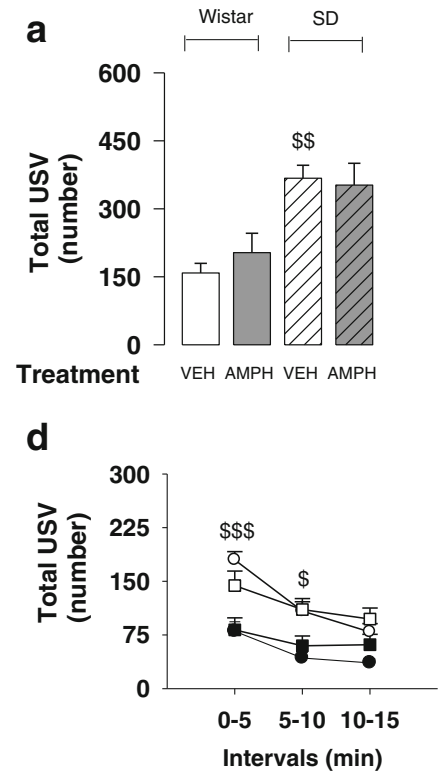
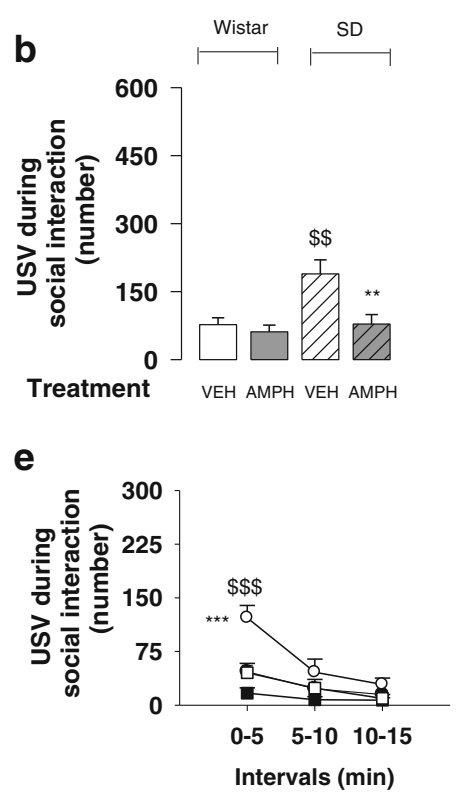

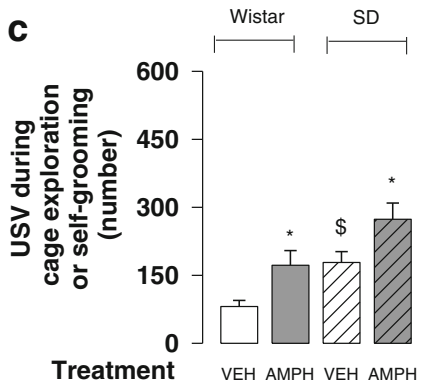

f

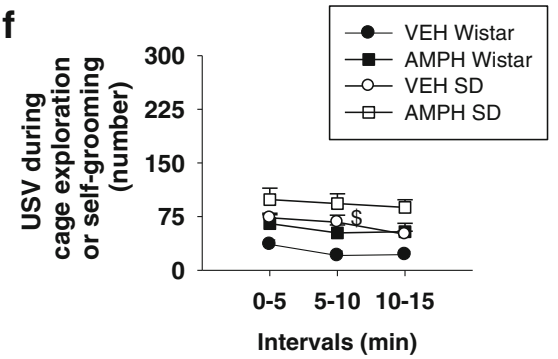

Fig. 6 Effects of amphetamine (AMPH; $0.2 \mathrm{mg} / \mathrm{kg}$, s.c., $30 \mathrm{~min}$ before test) on $50-\mathrm{kHz}$ ultrasonic vocalizations in adolescent Wistar and Sprague-Dawley rats during the social play behavior session. Vehicletreated Sprague-Dawley rats emitted more USVs than vehicle-treated Wistar rats during the 15-min test session (a), both during active social interaction (b) and during cage exploration or self-grooming (c). Sprague-Dawley rats treated with amphetamine emitted less USVs during active social interaction than vehicle-treated Sprague-Dawley rats (b). Conversely, amphetamine-treated Sprague-Dawley and Wistar rats emitted more USVs during cage exploration and self-grooming (c) than the corresponding vehicle-treated rats. When ultrasonic vocalizations were analyzed per 5-min interval, the total number of USVs was higher in vehicle-treated Sprague-Dawley than vehicle-treated Wistar rats during the first and the second 5-min intervals of the testing session (d). USV emitted selectively during either social interaction (e) or cage exploration and self-grooming (f) were higher in vehicle-treated Sprague-Dawley than vehicle-treated Wistar rats during the first and second 5-min intervals of the test, respectively. Amphetamine decreased the number of USVs emitted during social interaction only in SpragueDawley rats in the first 5-min interval (e). Data represent mean \pm SEM frequency of total USVs (a, d) and USVs either related $(\mathbf{b}, \mathbf{e})$ and unrelated $(\mathbf{c}, \mathbf{f})$ to the social interaction. ${ }^{*} p<0.05,{ }^{*} p<0.01$, ${ }^{* * *} p<0.001$ vs. vehicle treatment; ${ }^{\$} p<0.05,{ }^{\$} p<0.01 ;{ }^{\$} \${ }_{p}<0.001$ Sprague-Dawley vs. Wistar rats (Student-Newman-Keule post hoc test). $N=6-9$ per treatment group $p<0.001$; USVs during cage exploration or self-grooming in the second 5-min: $p<0.05$ ). Amphetamine decreased the number of USVs emitted during social interaction only in SpragueDawley rats in the first 5-min interval (Fig. 6e; $p<0.001$ ).

\section{Discussion}

Comparing different strains of rats or mice is a very useful approach to discover and map genetic influences on behavioral traits (Brand et al. 2012; Yilmazer-Hanke 2008). The aim of this study was to determine whether adolescent male Wistar and Sprague-Dawley rats show different patterns of social play behavior and USV emission during social interaction. Furthermore, we investigated whether adolescent rats from these two strains differ in the effects of acute morphine and amphetamine administration on social play behavior and USV production.

Wistar and Sprague-Dawley rat strains are extensively used in behavioral pharmacology studies. Certain behavioral differences between Wistar and Sprague-Dawley rats have been well characterized (Rex et al. 2004; Staples and
McGregor 2006; Walker et al. 2009; Zmarowski et al. 2012). For instance, Rex et al. (2004) found that adult Sprague-Dawley rats showed higher level of social interaction than adult Wistar rats when tested under high light levels, without any difference in locomotor activity. In addition, adult Sprague-Dawley and Wistar rats also spent more time on the open arms of the elevated plus-maze compared to Wistar rats (Rex et al. 2004). Differences in novelty-seeking behavior (Walker et al. 2009), cognitive performance (Zmarowski et al. 2012), and defensive response to predator odors (Staples and McGregor 2006) between adult Wistar and Sprague-Dawley rats have also been described. However, to our knowledge, differences in social play behavior and highfrequency USVs between adolescents of these strains have never been reported, and these cannot be easily inferred from across-laboratory comparisons.

We found that Sprague-Dawley rats exhibited higher levels of social play than Wistar rats: the frequency of pinning and pouncing, the two most characteristic expressions of social play behavior in rats, was higher in vehicle-treated adolescent Sprague-Dawley than in Wistar rats. These differences were most pronounced in the first $5 \mathrm{~min}$ of the test and were specific 
for play-related social behaviors, since the two strains did not differ in social behaviors not related to play, such as sniffing or social grooming. In both strains, social play declined over the 15-min test session. This is in line with previous findings showing that, when adolescent rats are tested under dim light in a familiar test cage, where the only novel stimulus is an unfamiliar test partner, levels of social play are already high in the first 5-min of the test period (Trezza and Vanderschuren 2008a; Vanderschuren et al. 1995a, b).

Social play behavior is a natural reinforcer (for reviews, see Trezza et al. 2010, 2011a; Vanderschuren 2010), and neurotransmitter systems implicated in the motivational, pleasurable, and cognitive aspects of natural and drug rewards, such as opioids, endocannabinoids, dopamine, and noradrenaline, play an important modulatory role in the performance of social play (Siviy and Panksepp 2011; Trezza et al. 2010; Vanderschuren et al. 1997). For instance, we and others have repeatedly shown that stimulation of $\mu$-opioid receptors by morphine or selective $\mu$-opioid receptor agonists enhances social play behavior, most likely by increasing the hedonic properties of social play (Panksepp et al. 1985; Trezza et al. 2011b; Trezza and Vanderschuren 2008b; Vanderschuren et al. 1995a). In addition, activation of $\alpha-2$ adrenoceptors by psychostimulants such as amphetamine and methylphenidate suppresses social play, possibly by interfering with cognitive aspects of the performance of social play behavior (Beatty et al. 1982, 1984; Thor and Holloway 1983; Vanderschuren et al. 2008). To evaluate whether adolescent Sprague-Dawley and Wistar rats may be equally useful in neuropharmacology studies of social play behavior, i.e., to assess the effects of drugs that may influence this behavior, we investigated whether rats from these two strains differed in the effects of acute morphine and amphetamine administration on social play behavior. On the basis of dose-response experiments performed separately in the two strains, the doses of morphine $1 \mathrm{mg} / \mathrm{kg}$ and amphetamine $0.2 \mathrm{mg} / \mathrm{kg}$ were selected for strain comparison experiments. Morphine increased social play behavior in both strains, although its effects were more pronounced in Wistar than Sprague-Dawley rats. Thus, Wistar rats treated with morphine showed a threefold increase in pinning and pouncing frequencies compared to Wistar rats treated with vehicle; in SpragueDawley rats, morphine induced a trend for an increase in pinning and significantly increased pouncing. It has previously been shown that morphine increases social play as a whole, without altering the sequential structure of this behavior (Vanderschuren et al. 1995c). Therefore, in line with the higher levels of social play displayed by vehicle-treated animals at the beginning of the test period, we found that in Wistar rats morphine increased social play in the first and second interval of the testing session, while this happened in Sprague-Dawley rats in the first interval only.

The effects of amphetamine on social play were qualitatively and quantitatively similar in Wistar and Sprague-
Dawley rats, with the drug reducing pinning and pouncing frequencies to the same extent in adolescent rats from both strains. In both strains, morphine and amphetamine did not alter social exploratory behavior, thus confirming previous findings (Beatty et al. 1982; Sutton and Raskin 1986; Trezza and Vanderschuren 2008a; Vanderschuren et al. 2008) showing that opioid and psychostimulants effects on social play are behaviorally specific, i.e., not secondary to general changes in locomotion or social interest. Taken together, our results show that morphine increased and amphetamine decreased social play behavior in both Wistar and Sprague-Dawley rats. However, the play-enhancing effects of morphine were more pronounced in Wistar than Sprague-Dawley animals. The higher baseline levels of social play behavior displayed by vehicle-treated Sprague-Dawley compared to vehicle-treated Wistar rats likely account for this finding. These strain differences should be taken into account when testing the effects of drugs that increase social play behavior, in order to avoid possible ceiling effects.

In our experiments, we measured the number of $50-\mathrm{kHz}$ USVs emitted during the testing session. In particular, we discriminated between the $50-\mathrm{kHz}$ USVs emitted during actual social interaction from those emitted during the performance of non-social behaviors, such as cage exploration or self-grooming. We did not find a positive correlation between the performance of social behaviors and the emission of 50-kHz USVs. In fact, vehicle-treated adolescents from both strains emitted a similar number of $50-\mathrm{kHz}$ USVs while performing non-social behaviors (i.e., cage exploration or self-grooming) or social activities (calculated as the sum of social behaviors both related and unrelated to play). Both categories of $50-\mathrm{kHz}$ USVs were higher in vehicle-treated Sprague-Dawley than Wistar rats. In both strains, morphine administration did not affect the number of USVs emitted during the 15-min testing session, neither while animals were engaged in social activities nor in general exploration. In both Wistar and Sprague-Dawley rats, amphetamine administration increased USV emission during cage exploration, which is in line with previous findings showing increases in $50-\mathrm{kHz}$ USVs in amphetamine-treated Sprague-Dawley and Wistar rats (e.g., Burgdorf et al. 2001; Thompson et al. 2006). In Sprague-Dawley animals only, amphetamine decreased USVs during social interaction.

Controversial data exist in the literature about whether 50$\mathrm{kHz}$ USVs may reflect the rewarding value of adolescent social interactions. Knutson and coworkers were the first to suggest that $50-\mathrm{kHz}$ USVs may index play motivation in rats. They found that adolescent Long-Evans rats emitted more $50-\mathrm{kHz}$ USVs while playing together than while alone (Knutson et al. 1998). Interestingly, rats separated from the play partner through a screen dividing the testing chamber, but given the opportunity to play the day before, vocalized more than rats that played both days. Conversely, separated rat pairs 
that had not played before vocalized less than rats that played on both days. On the basis of these data, the authors suggested that one trial of play is sufficient to induce a motivational state that evokes $50-\mathrm{kHz}$ USVs in rats and that general motor activity alone cannot account for the expression of these vocalizations (Knutson et al. 1998, 2002). However, not all data support the use of 50-kHz USVs in adolescent rats as an index of positive affective state during active social interaction or anticipation for social contact. Thus, Willey et al. found that adolescent Sprague-Dawley rats emit fewer $50-\mathrm{kHz}$ USVs than adults in anticipation of a social partner (Willey and Spear 2012) and during social interactions (Willey et al. 2009), although adolescent rats usually engage in higher levels of social behaviors, especially social play behavior (Varlinskaya and Spear 2002; 2008; Willey and Spear 2013; Willey et al. 2009) and show greater conditioned place preference for a social stimulus than adults (Douglas et al. 2004). Together with our data, these findings suggest that the emission of $50-\mathrm{kHz}$ USVs and the behavioral parameters typically thought to measure the rewarding value of social interactions in adolescent rats can be dissociable and may rely on different neurobehavioral mechanisms. In line with this hypothesis, it has been shown that a dissociation exists between the emission of $50-\mathrm{kHz}$ USVs and behavioral measures of affective responses during drug self-administration or anticipation. Thus, while $50-\mathrm{kHz}$ USVs can be elicited by administration of psychostimulant drugs (Barker et al. 2010; Browning et al. 2011; Burgdorf et al. 2000; Burgdorf and Panksepp 2006; Knutson et al. 1998; Maier et al. 2010; Simola et al. 2012; Thompson et al. 2006; Trezza et al. 2010; Wintink and Brudzynski 2001), rewarding doses of morphine, MDMA, and nicotine have been related to no changes or even decreases in $50-\mathrm{kHz}$ USV emission (Hamed et al. 2012; Sadananda et al. 2012; Simola et al. 2012; Wright et al. 2012).

To summarize, two conclusions can be drawn from the present study. First, strain differences in baseline levels of social play behavior exist between adolescent Wistar and Sprague-Dawley rats, with the latter showing higher levels of social play than the former.

Morphine and amphetamine increased and decreased social play behavior, respectively, in the two strains. However, while morphine significantly increased pinning and pouncing frequencies in Wistar rats, it failed to significantly increase pinning in Sprague-Dawley adolescents. Thus, when performing pharmacological manipulations of social play, researchers should be aware that the magnitude of druginduced changes in social play parameters may differ in these two strains, and this needs to be considered in order to avoid ceiling or floor effects. Second, we show that positive social interactions in adolescent rats do not necessarily correlate with 50-kHz USVs emission and that, under the testing conditions used in the present study, drugs that affected social play did not affect USV production during social interactions. Thus, it cannot generally be assumed that $50-\mathrm{kHz}$ USVs index positive affective states during social interactions.

Acknowledgments This study was supported by Veni grant 91611052 (Nederlandse Organisatie voor Wetenschappelijk Onderzoek, V.T.), Marie Curie Career Reintegration Grant PCIG09-GA-2011-293589 (Seventh Framework Programme People, V.T.), and Futuro in Ricerca 2010 (Italian Ministry for University and Scientific Research, V.T., P.C.). We thank Andrea Peloso, Lidia Montebello, and Alessandro Pasquale (Master students, Department of Physiology and Pharmacology, Sapienza, University of Rome) for their technical help.

\section{References}

Alessandri SM (1992) Attention, play, and social behavior in ADHD preschoolers. J Abnorm Child Psychol 20:289-302

Baarendse PJJ, Counotte DS, O'Donnell P, Vanderschuren LJMJ (2013) Early social experience is critical for the development of cognitive control and dopamine modulation of prefrontal cortex function. Neuropsychopharmacology 38(8):1485-1494

Barker DJ, Root DH, Ma S, Jha S, Megehee L, Pawlak AP, West MO (2010) Dose-dependent differences in short ultrasonic vocalizations emitted by rats during cocaine self-administration. Psychopharmacology (Berl) $211: 435-442$

Beatty WW, Costello KB, Berry SL (1984) Suppression of play fighting by amphetamine: effects of catecholamine antagonists, agonists and synthesis inhibitors. Pharmacol, Biochem Behav 20:747-755

Beatty WW, Dodge AM, Dodge LJ, White K, Panksepp J (1982) Psychomotor stimulants, social deprivation and play in juvenile rats. Pharmacol, Biochem Behav 16:417-422

Bolanos CA, Glatt SJ, Jackson D (1998) Subsensitivity to dopaminergic drugs in periadolescent rats: a behavioral and neurochemical analysis. Brain Res Dev Brain Res 111:25-33

Brand T, Spanagel R, Schneider M (2012) Decreased reward sensitivity in rats from the Fischer344 strain compared to Wistar rats is paralleled by differences in endocannabinoid signaling. PLoS One 7:e31169

Browning JR, Browning DA, Maxwell AO, Dong Y, Jansen HT, Panksepp J, Sorg BA (2011) Positive affective vocalizations during cocaine and sucrose self-administration: a model for spontaneous drug desire in rats. Neuropharmacology 61:268-275

Burgdorf J, Knutson B, Panksepp J (2000) Anticipation of rewarding electrical brain stimulation evokes ultrasonic vocalization in rats. Behav Neurosci 114:320-327

Burgdorf J, Knutson B, Panksepp J, Ikemoto S (2001) Nucleus accumbens amphetamine microinjections unconditionally elicit $50-\mathrm{kHz}$ ultrasonic vocalizations in rats. Behav Neurosci 115:940-944

Burgdorf J, Panksepp J (2006) The neurobiology of positive emotions. Neurosci Biobehav Rev 30:173-187

Burgdorf J, Panksepp J, Brudzynski SM, Kroes R, Moskal JR (2005) Breeding for $50-\mathrm{kHz}$ positive affective vocalization in rats. Behav Genet 35:67-72

Burgdorf J, Panksepp J, Moskal JR (2011) Frequency-modulated $50 \mathrm{kHz}$ ultrasonic vocalizations: a tool for uncovering the molecular substrates of positive affect. Neurosci Biobehav Rev 35:1831-1836

Calcagnetti DJ, Schechter MD (1992) Place conditioning reveals the rewarding aspect of social interaction in juvenile rats. Physiol Behav 51:667-672

Clause BT (1993) The Wistar Rat as a right choice: establishing mammalian standards and the ideal of a standardized mammal. J Hist Biol 26:329-349 
Crowder WF, Hutto CW Jr (1992) Operant place conditioning measures examined using two nondrug reinforcers. Pharmacol, Biochem Behav 41:817-824

Douglas LA, Varlinskaya EI, Spear LP (2004) Rewarding properties of social interactions in adolescent and adult male and female rats: impact of social versus isolate housing of subjects and partners. Dev Psychobiol 45:153-162

Ebstein RP, Israel S, Chew SH, Zhong S, Knafo A (2010) Genetics of human social behavior. Neuron 65:831-844

Falk JL (1958) The grooming behavior of the chimpanzee as a reinforcer. J Exp Anal Behav 1:83-85

Ferguson SA, Cada AM (2004) Spatial learning/memory and social and nonsocial behaviors in the spontaneously hypertensive, WistarKyoto and Sprague-Dawley rat strains. Pharmacol, Biochem Behav 77:583-594

Field EF, Pellis SM (1994) Differential effects of amphetamine on the attack and defense components of play fighting in rats. Physiol Behav 56:325-330

Fowler SC, Birkestrand B, Chen R, Vorontsova E, Zarcone T (2003) Behavioral sensitization to amphetamine in rats: changes in the rhythm of head movements during focused stereotypies. Psychopharmacology (Berl) 170:167-177

Hamed A, Taracha E, Szyndler J, Krzascik P, Lehner M, Maciejak P, Skorzewska A, Plaznik A (2012) The effects of morphine and morphine conditioned context on $50 \mathrm{kHz}$ ultrasonic vocalisation in rats. Behav Brain Res 229:447-450

Hedrich HJ (2006) Taxonomy and stocks and strains. In: Suckow MA, Weisbroth SH, Franklin CH (eds) The laboratory rat. Elsevier, Burlington

Humphreys AP, Einon DF (1981) Play as a reinforcer for maze learning in juvenile rats. Anim Behav 29:259-270

Ikemoto S, Panksepp J (1992) The effects of early social isolation on the motivation for social play in juvenile rats. Dev Psychobiol 25:261274

Jordan R (2003) Social play and autistic spectrum disorders: a perspective on theory, implications and educational approaches. Autism 7:347-360

Kinney GG, Wilkinson LO, Saywell KL, Tricklebank MD (1999) Rat strain differences in the ability to disrupt sensorimotor gating are limited to the dopaminergic system, specific to prepulse inhibition, and unrelated to changes in startle amplitude or nucleus accumbens dopamine receptor sensitivity. J Neurosci 19:5644-5653

Knutson B, Burgdorf J, Panksepp J (1998) Anticipation of play elicits high-frequency ultrasonic vocalizations in young rats. J Comp Psychol 112:65-73

Knutson B, Burgdorf J, Panksepp J (2002) Ultrasonic vocalizations as indices of affective states in rats. Psychol Bull 128:961-977

Kuczenski R, Segal DS (1999) Sensitization of amphetamine-induced stereotyped behaviors during the acute response: role of D1 and D2 dopamine receptors. Brain Res 822:164-174

Lahvis GP, Alleva E, Scattoni ML (2011) Translating mouse vocalizations: prosody and frequency modulation. Genes Brain Behav 10:4-16

Magnus-Ellenbroek B, Havemann-Reinecke U (1993) Morphineinduced hyperactivity in rats-a rebound effect? Naunyn Schmiedebergs Arch Pharmacol 347:635-642

Maier EY, Ma ST, Ahrens A, Schallert TJ, Duvauchelle CL (2010) Assessment of ultrasonic vocalizations during drug selfadministration in rats. J Vis Exp pii: 2041.

Manning MM, Wainwright LD (2010) The role of high level play as a predictor social functioning in autism. J Autism Dev Disord 40(5): 523-533

Mas M, Sabater E, Olaso MJ, Horga JF, Faura CC (2000) Genetic variability in morphine sensitivity and tolerance between different strains of rats. Brain Res 866:109-115

Mason WM, Saxon SV, Sharpe LG (1963) Preferential responses of young chimpanzees to food and social rewards. Psychol Rec 13: 341-345
McDermott C, Kelly JP (2008) Comparison of the behavioural pharmacology of the Lister-Hooded with 2 commonly utilised albino rat strains. Prog Neuropsychopharmacol Biol Psychiatry 32:18161823

Meyer-Lindenberg A, Tost H (2012) Neural mechanisms of social risk for psychiatric disorders. Nat Neurosci 15:663-668

Niesink RJ, Van Ree JM (1989) Involvement of opioid and dopaminergic systems in isolation-induced pinning and social grooming of young rats. Neuropharmacology 28:411-418

Normansell L, Panksepp J (1990) Effects of morphine and naloxone on play-rewarded spatial discrimination in juvenile rats. Dev Psychobiol 23:75-83

O'Connell LA, Hofmann HA (2010) Genes, hormones, and circuits: an integrative approach to study the evolution of social behavior. Front Neuroendocrinol 32:320-335

Panksepp J, Beatty WW (1980) Social deprivation and play in rats. Behav Neural Biol 30:197-206

Panksepp J, Jalowiec J, DeEskinazi FG, Bishop P (1985) Opiates and play dominance in juvenile rats. Behav Neurosci 99:441-453

Panksepp J, Siviy S, Normansell L (1984) The psychobiology of play: theoretical and methodological perspectives. Neurosci Biobehav Rev 8:465-492

Pellis SM, McKenna M (1992) Intrinsic and extrinsic influences on play fighting in rats: effects of dominance, partner's playfulness, temperament and neonatal exposure to testosterone propionate. Behav Brain Res 50:135-145

Pellis SM, Pellis V (1987) Play-fighting differs from serious fighting in both target of attack and tactics of fighting in the laboratory rat Rattus norvegicus. Aggress Behav 13:227-242

Pellis SM, Pellis V (2009) The playful brain: venturing to the limits of neuroscience. Oneworld Publications, Oxford, UK

Pellis SM, Pellis VC, Dewsbury DA (1989) Different levels of complexity in the play fighting of muroid rodents appear to result from different levels of intensity of attack and defense. Aggress Behav 15:297-310

Poole TB, Fish J (1975) An investigation of playful behavior in Rattus norvegicus and Mus musculus (Mammalia). J Zool 175:61-71

Reinhart CJ, McIntyre DC, Metz GA, Pellis SM (2006) Play fighting between kindling-prone (FAST) and kindling-resistant (SLOW) rats. J Comp Psychol 120:19-30

Rex A, Voigt JP, Gustedt C, Beckett S, Fink H (2004) Anxiolytic-like profile in Wistar, but not Sprague-Dawley rats in the social interaction test. Psychopharmacology (Berl) 177:23-34

Sadananda M, Natusch C, Karrenbauer B, Schwarting RK (2012) $50-\mathrm{kHz}$ calls in rats: effects of MDMA and the 5-HT(1A) receptor agonist 8OH-DPAT. Pharmacol, Biochem Behav 101:258-264

Scattoni ML, Crawley J, Ricceri L (2009) Ultrasonic vocalizations: a tool for behavioural phenotyping of mouse models of neurodevelopmental disorders. Neurosci Biobehav Rev 33:508-515

Shoaib M, Spanagel R, Stohr T, Shippenberg TS (1995) Strain differences in the rewarding and dopamine-releasing effects of morphine in rats. Psychopharmacology (Berl) 117:240-247

Simola N, Fenu S, Costa G, Pinna A, Plumitallo A, Morelli M (2012) Pharmacological characterization of 50-kHz ultrasonic vocalizations in rats: comparison of the effects of different psychoactive drugs and relevance in drug-induced reward. Neuropharmacology 63:224-234

Siviy SM, Crawford CA, Akopian G, Walsh JP (2011) Dysfunctional play and dopamine physiology in the Fischer 344 rat. Behav Brain Res 220:294-304

Siviy SM, Love NJ, DeCicco BM, Giordano SB, Seifert TL (2003) The relative playfulness of juvenile Lewis and Fischer-344 rats. Physiol Behav 80:385-394

Siviy SM, Panksepp J (1987) Juvenile play in the rat: thalamic and brain stem involvement. Physiol Behav 41:103-114

Siviy SM, Panksepp J (2011) In search of the neurobiological substrates for social playfulness in mammalian brains. Neurosci Biobehav Rev $35: 1821-1830$ 
Spinka M, Newberry RC, Bekoff M (2001) Mammalian play: training for the unexpected. Q Rev Biol 76:141-168

Staples LG, McGregor IS (2006) Defensive responses of Wistar and Sprague-Dawley rats to cat odour and TMT. Behav Brain Res 172:351-354

Sutton ME, Raskin LA (1986) A behavioral analysis of the effects of amphetamine on play and locomotor activity in the post-weaning rat. Pharmacol, Biochem Behav 24:455-461

Takahashi N, Kashino M, Hironaka N (2010) Structure of rat ultrasonic vocalizations and its relevance to behavior. PLoS One 5:e14115

Thiel KJ, Okun AC, Neisewander JL (2008) Social reward-conditioned place preference: a model revealing an interaction between cocaine and social context rewards in rats. Drug Alcohol Depend 96:202-212

Thiel KJ, Sanabria F, Neisewander JL (2009) Synergistic interaction between nicotine and social rewards in adolescent male rats. Psychopharmacology (Berl) 204:391-402

Thompson B, Leonard KC, Brudzynski SM (2006) Amphetamineinduced $50 \mathrm{kHz}$ calls from rat nucleus accumbens: a quantitative mapping study and acoustic analysis. Behav Brain Res 168:64-73

Thor DH, Holloway WR Jr (1983) Play soliciting in juvenile male rats: effects of caffeine, amphetamine and methylphenidate. Pharmacol, Biochem Behav 19:725-727

Trezza V, Baarendse PJJ, Vanderschuren LJMJ (2009) Prosocial effects of nicotine and ethanol in adolescent rats through partially dissociable neurobehavioral mechanisms. Neuropsychopharmacology 34: 2560-2573

Trezza V, Baarendse PJJ, Vanderschuren LJMJ (2010) The pleasures of play: pharmacological insights into social reward mechanisms. Trends Pharmacol Sci 31:463-469

Trezza V, Campolongo P, Cassano T, Macheda T, Dipasquale P, Carratu MR, Gaetani S, Cuomo V (2008) Effects of perinatal exposure to delta9-tetrahydrocannabinol on the emotional reactivity of the offspring: a longitudinal behavioral study in Wistar rats. Psychopharmacology (Berl) 198:529-537

Trezza V, Campolongo P, Vanderschuren LJMJ (2011a) Evaluating the rewarding nature of social interactions in laboratory animals. Dev Cogn Neurosci 1:444-458

Trezza V, Damsteegt R, Achterberg EJM, Vanderschuren LJMJ (2011b) Nucleus accumbens mu-opioid receptors mediate social reward. J Neurosci 31:6362-6370

Trezza V, Vanderschuren LJMJ (2008a) Bidirectional cannabinoid modulation of social behavior in adolescent rats. Psychopharmacology (Berl) 197:217-227

Trezza V, Vanderschuren LJMJ (2008b) Cannabinoid and opioid modulation of social play behavior in adolescent rats: differential behavioral mechanisms. Eur Neuropsychopharmacol 18:519-530

Van den Berg CL, Pijlman FT, Koning HA, Diergaarde L, Van Ree JM, Spruijt BM (1999) Isolation changes the incentive value of sucrose and social behaviour in juvenile and adult rats. Behav Brain Res 106:133-142

Vanderschuren LJMJ, Niesink RJM, Spruijt BM, Van Ree JM (1995a) Effects of morphine on different aspects of social play in juvenile rats. Psychopharmacology (Berl) 117:225-231

Vanderschuren LJMJ, Niesink RJM, Spruijt BM, Van Ree JM (1995b) Influence of environmental factors on social play behavior of juvenile rats. Physiol Behav 58:119-123
Vanderschuren LJMJ, Spruijt BM, Hol T, Niesink RJM, Van Ree JM (1995c) Sequential analysis of social play behavior in juvenile rats: effects of morphine. Behav Brain Res 72:89-95

Vanderschuren LJMJ (2010) How the brain makes play fun. Am J Play 2: 315-337

Vanderschuren LJMJ, Niesink RJ, Van Ree JM (1997) The neurobiology of social play behavior in rats. Neurosci Biobehav Rev 21:309326

Vanderschuren LJMJ, Trezza V, Griffioen-Roose S, Schiepers OJG, Van Leeuwen N, De Vries TJ, Schoffelmeer ANM (2008) Methylphenidate disrupts social play behavior in adolescent rats. Neuropsychopharmacology 33:2946-2956

Varlinskaya EI, Spear LP (2002) Acute effects of ethanol on social behavior of adolescent and adult rats: role of familiarity of the test situation. Alcohol Clin Exp Res 26:1502-1511

Varlinskaya EI, Spear LP (2008) Social interactions in adolescent and adult Sprague-Dawley rats: impact of social deprivation and test context familiarity. Behav Brain Res 188:398-405

Vezina P, Queen AL (2000) Induction of locomotor sensitization by amphetamine requires the activation of NMDA receptors in the rat ventral tegmental area. Psychopharmacology (Berl) 151: 184-191

Von Frijtag JC, Schot M, van den Bos R, Spruijt BM (2002) Individual housing during the play period results in changed responses to and consequences of a psychosocial stress situation in rats. Dev Psychobiol 41(1):58-69

Walker FR, Naicker S, Hinwood M, Dunn N, Day TA (2009) Strain differences in coping behaviour, novelty seeking behaviour, and susceptibility to socially conditioned fear: a comparison between Wistar and Sprague Dawley rats. Stress 12:507-516

Willey AR, Spear LP (2012) Development of anticipatory $50 \mathrm{kHz}$ USV production to a social stimuli in adolescent and adult male SpragueDawley rats. Behav Brain Res 226:613-618

Willey AR, Spear LP (2013) The effects of pre-test social deprivation on a natural reward incentive test and concomitant $50 \mathrm{kHz}$ ultrasonic vocalization production in adolescent and adult male SpragueDawley rats. Behav Brain Res 245:107-112

Willey AR, Varlinskaya EI, Spear LP (2009) Social interactions and 50$\mathrm{kHz}$ ultrasonic vocalizations in adolescent and adult rats. Behav Brain Res 202:122-129

Wintink AJ, Brudzynski SM (2001) The related roles of dopamine and glutamate in the initiation of $50-\mathrm{kHz}$ ultrasonic calls in adult rats. Pharmacol, Biochem Behav 70:317-323

Wohr M, Schwarting RK (2013) Affective communication in rodents: ultrasonic vocalizations as a tool for research on emotion and motivation. Cell Tissue Res

Wright JM, Deng L, Clarke PB (2012) Failure of rewarding and locomotor stimulant doses of morphine to promote adult rat $50-\mathrm{kHz}$ ultrasonic vocalizations. Psychopharmacology (Berl) 224:477-487

Yilmazer-Hanke DM (2008) Morphological correlates of emotional and cognitive behaviour: insights from studies on inbred and outbred rodent strains and their crosses. Behav Pharmacol 19:403-434

Zmarowski A, Beekhuijzen M, Lensen J, Emmen H (2012) Differential performance of Wistar Han and Sprague Dawley rats in behavioral tests: differences in baseline behavior and reactivity to positive control agents. Reprod Toxicol 34:192-203 